\title{
Altered Dopamine Modulation of Inhibition in the Prefrontal Cortex of Cocaine-Sensitized Rats
}

\author{
Sven Kroener*,' and Antonieta Lavin' \\ 'Department of Neurosciences, Medical University of South Carolina, Charleston, SC, USA
}

\begin{abstract}
A functionally hypoactive prefrontal cortex (PFC) is thought to contribute to decreased cognitive inhibitory control over drug-seeking behavior in cocaine addicts. Alterations in PFC dopamine (DA) and $\gamma$-aminobutyric acid (GABA) transmission are involved in the development of behavioral sensitization to cocaine, and repeated exposure to cocaine decreases DA D2 receptor (D2R) function in the PFC. We used recordings in PFC slices from adult rats to investigate how repeated cocaine treatment followed by 2 weeks of withdrawal affects DA modulation of GABA transmission and interneuron firing. In agreement with previous results in drug-naive animals we found that in saline-treated control animals DA $(20 \mu \mathrm{M})$ modulated evoked inhibitory post-synaptic currents (elPSCs) in a biphasic, time- and receptor-dependent manner. Activation of D2Rs transiently reduced, whereas DI receptor activation persistently increased the amplitude of elPSCs. In cocaine-sensitized animals the D2R-dependent modulation of eIPSCs was abolished and the time course of DA effects was altered. In both saline- and cocaine-treated animals the effects of DA on elPSCs were paralleled by distinct changes in spontaneous IPSCs (sIPSCs). In cocaine-treated animals the alterations in DA modulation of elPSCs and sIPSCs correlated with a lack of D2R-specific reduction in action potential-independent GABA release, which might normally oppose DI-dependent increases in GABA transmission. Recordings from interneurons furthermore show that D2R activation can increase current-evoked spike firing in saline, but not in cocaine-treated animals. Altered DA regulation of inhibition during cocaine withdrawal could disturb normal cortical processing and contribute to a hypoactive PFC.

Neuropsychopharmacology (2010) 35, 2292-2304; doi: I0.1 038/npp.20 I0.107; published online 21 July 2010
\end{abstract}

Keywords: prefrontal cortex; GABA; D2 receptor; DI receptor; electrophysiology; addiction

\section{INTRODUCTION}

Addiction to cocaine involves neurobiological changes in limbic and cortical circuits that mediate a variety of cognitive and emotional processes. Several lines of evidence suggest that a functionally 'hypoactive' frontal cortex results in decreased cognitive inhibitory control to regulate drugseeking behavior. Areas of the prefrontal cortex (PFC) are activated in addicted subjects during intoxication and exposure to drug-associated cues, but they are deactivated during withdrawal (Goldstein and Volkow, 2002; Bolla et al, 2004). Similarly, in rats inhibition of the medial frontal cortex blocks reinstatement of drug seeking (McFarland and Kalivas, 2001; McLaughlin and See, 2003; McFarland et al, 2004), and the suppression of drug seeking during extinction requires activation of the infralimbic cortex (Peters et al, 2008). Interestingly, cue-induced drug-seeking selectively increases the expression of the immediate early

*Correspondence: Dr S Kroener, School of Behavioral and Brain Sciences, University of Texas at Dallas, 800 West Campbell Rd., GR4I, Richardson TX75080, USA. Tel: + | 972883 2039, Fax: + | 972882 249 |; E-mail: kroener@utdallas.edu

Received 31 March 20 I0; revised I 5 June 20 I0; accepted 24 June 2010 gene $c$-Fos in interneurons of the PFC, although at the same time it reduces markers of activity in pyramidal cells (Miller and Marshall, 2004). Similarly, cocaine-sensitized animals showed an increase in extracellular $\gamma$-aminobutyric acid (GABA) in the medial PFC (Jayaram and Steketee, 2005). These results suggest that in cocaine-sensitized animals interneurons may be preferentially activated, whereas the overall PFC output (the activity of pyramidal cells) is attenuated. Dopamine (DA) projections from the VTA provide a modulatory input to the PFC that is essential for optimal cognitive performance and this projection may be involved in sensitization processes (Brozoski et al, 1979; Steketee, 2003). Animals with a history of cocaine selfadministration show deficits in tasks that require an intact medial PFC, an effect that is accompanied by a significant decrease in D2 receptors (D2Rs) (Briand et al, 2008). Activation of D2Rs in the PFC of sensitized animals is less effective because of the elevated levels of AGS3, a member of a family of $G$ protein regulators that decreases signaling through Gi- $\alpha$ (Bowers et al, 2004). Dopaminergic fibers contact both pyramidal cells and GABAergic interneurons in the PFC of rats and primates (LeMoine and Gaspar, 1998; Sesack et al, 1995), and D2R activation modulates interneuron activity and GABAergic synaptic transmission 
in drug-naïve animals (Seamans et al, 2001; TranthamDavidson et al, 2004; Tseng and O'Donnell, 2007).

We used whole-cell recordings in PFC slices from adult animals treated repeatedly with cocaine and then subjected to long-term withdrawal, to assess changes in the DAergic modulation of PFC interneurons and GABAergic transmission. We hypothesized that in cocaine-sensitized animals the effect of D2R activation is blunted, so that D1 receptor (D1R)-dependent increases in GABAergic synaptic transmission dominate. Our results support this idea, showing that the D2R-dependent transient reduction in the amplitude of synaptically evoked inhibitory post-synaptic currents (eIPSCs) seen in saline-treated rats is abolished in cocainesensitized animals. In contrast, both in saline- and cocainetreated animals D1R-dependent modulation of IPSCs was unaffected, leading to increased eIPSC amplitudes, which was paralleled by an increase in the frequency of spontaneous IPSCs (sIPSCs). In saline-treated animals, the effects of D1R stimulation were at least partly countered by a D2Rdependent reduction of GABA release measured as action potential-independent release of miniature IPSCs. In cocainetreated animals, this D2R-dependent reduction in GABA release was not observed. Moreover, current-clamp recordings from interneurons also show that D2R modulation of spike firing is disrupted in cocaine-sensitized animals. Taken together, these results show opposing D1R and D2Rdependent mechanisms that contribute to DA modulation of GABAergic synaptic transmission in the cortex of salinetreated animals. Chronic exposure to cocaine and withdrawal induces behavioral sensitization, selectively disrupts D2Rdependent signaling. Altered DA regulation of inhibition during cocaine withdrawal could disturb normal cortical processing and contribute to a hypoactive PFC.

\section{MATERIALS AND METHODS}

All procedures were carried out in accordance with the NIH Guide for the Care and Use of Laboratory Animals, and were approved by the Medical University of South Carolina Animal Care and Use Committee. Subjects were adult male Sprague-Dawley rats (Charles River Laboratories, Wilmington, MA, USA), which were older than 50 days before the start of the experiment. Animals were housed in pairs in a temperature-controlled colony room on a $12 \mathrm{~h}$ light/dark cycle (lights on at 7:00 AM), and food and water were available ad libitum. Animals were allowed to acclimatize to the colony room for 3-5 days after their arrival before they were divided into two treatment groups: animals in the control group received daily intraperitoneal (IP) injections of saline for 7 days, while animals in the cocaine group received daily injections of cocaine hydrochloride in saline (Sigma, St Louis, MO, USA) using a dosing regimen previously described to produce locomotor sensitization (Pierce et al, 1996; Bowers et al, 2004). On the first and last days of cocaine administration, the rats were injected with $15 \mathrm{mg} / \mathrm{kg}$ cocaine IP. On the intervening days, the animals were injected with $30 \mathrm{mg} / \mathrm{kg}$ cocaine IP. Both groups of animals were subjected to a 2-week withdrawal after the last injection of saline or cocaine. On the first day of drug administration and after the withdrawal period, the motor activity of animals in both groups was monitored in a photocell apparatus (Omnitech, Columbus, OH, USA), as described elsewhere (Pierce et al, 1996). Briefly, animals were placed in the photocell cages for $1 \mathrm{~h}$ time after which they were removed from the cages, injected with cocaine or saline, respectively, and returned to the photocell cages for an additional $2 \mathrm{~h}$. Consistent with previous studies (Pierce et al, 1996), the cocaine treatment produced locomotor sensitivity. The total distance traveled during the first hour after cocaine injection $(15 \mathrm{mg} / \mathrm{kg})$ was significantly increased after 2 weeks of withdrawal when compared with the activity on the first day of cocaine treatment (day 1: $1500.7 \pm 260.0 \mathrm{~cm}$; day 23: $3523.3 \pm 741.3 \mathrm{~cm}$; paired Student's $t$-test, $p<0.01)$. Animals were killed the following day for the preparation of brain slices. The experimenter was not blind to the treatment condition of the animal on the day of the electrophysiological recordings.

\section{Brain Slice Preparation and Electrophysiology}

Saline- or cocaine-treated rats (72-100-day-old) were deeply anesthetized with an IP injection of chloral hydrate $(400 \mathrm{mg} /$ $\mathrm{kg}$ ) and transcardially perfused with an ice-cold highsucrose substituted ACSF (in $\mathrm{mM}$ ): 230 sucrose, $1.9 \mathrm{KCl}, 1.2$ $\mathrm{Na}_{2} \mathrm{HPO}_{4}, 33 \mathrm{NaHCO}_{3}, 6 \mathrm{MgCl}_{2}, 0.5 \mathrm{CaCl}_{2}, 10$ glucose, and 0.4 ascorbic acid. Coronal slices $(350 \mu \mathrm{m})$ were cut on a vibratome (Leica, VT1000S or VT1200S, Nussloch, Germany). Slices were incubated at room temperature for at least $1 \mathrm{~h}$ in a solution consisting of (in $\mathrm{mM}$ ): $125 \mathrm{NaCl}, 2.5$ $\mathrm{KCl}, 1.25 \mathrm{Na}_{2} \mathrm{HPO}_{4}$, 10 glucose, $25 \mathrm{NaHCO}_{3}, 6 \mathrm{MgCl}_{2}$, and 1 $\mathrm{CaCl}_{2}$. Finally, slices were transferred to a submersion-type recording chamber and recordings were performed at $33 \pm 1{ }^{\circ} \mathrm{C}$ using a recording ACSF consisting of (in $\mathrm{mM}$ ): $125 \mathrm{NaCl}, 2.5 \mathrm{KCl}, 25 \mathrm{NaHCO}_{3}, 1.3 \mathrm{MgCl}_{2}, 2 \mathrm{CaCl}_{2}, 10$ glucose, and 0.4 ascorbic acid at a rate of $1-2 \mathrm{ml} / \mathrm{min}$. All ACSF solutions were constantly aerated with a mixture of $95 \% \mathrm{O}_{2}-5 \% \mathrm{CO}_{2}$ to maintain $\sim 7.2 \mathrm{pH}$. Whole-cell recordings were obtained from neurons in layers 5 and 6 of the prelimbic cortex (between 3.7 and $2 \mathrm{~mm}$ from bregma) using differential interference contrast optics (Axioskop, Zeiss, Thornwood, NY) and videomicroscopy (Dage-MTI, Michigan City, IN, USA). For voltage-clamp recordings electrodes (3-5 MOhm open tip resistance) were filled with (in mM): $130 \mathrm{CsCl}, 20$ TEA, 10 HEPES, $2 \mathrm{MgCl}_{2}$, 0.5 EGTA, 4 Na-ATP, 0.3 Na-GTP, 14 phospocreatine, and 2 QX-314. For current-clamp recordings, electrodes were filled with a solution containing (in $\mathrm{mM}$ ): $125 \mathrm{~K}$-gluconate, 10 HEPES, $20 \mathrm{KCl}, 4$ ATP-Mg, 0.3 GTP-Na, 14 phosphocreatine, and 0.4 Alexa 594.

\section{Data Collection and Analysis}

Recordings were obtained with a Multiclamp 700B amplifier (Molecular Devices, Mississauga, ON, Canada). Membrane potential was not corrected for changes in junction potential after break-in. Signals were low-pass filtered at $3 \mathrm{kHz}$ and digitized at $10 \mathrm{kHz}$. Data were stored on PC for off-line analysis. Data acquisition and analysis were performed using software written in LabView (National Instruments, Austin, TX, USA) or Axograph-X (J. Clements, Sydney, Australia). In voltage-clamp experiments, we examined both evoked and sIPSCs. The membrane potential was held at $-80 \mathrm{mV}$ and GABA-mediated events were pharmaco- 
logically isolated by adding $20 \mu \mathrm{M}$ 6-cyano-7-nitroquinoxaline-2,3-dione (to block AMPA receptors) and $50 \mu \mathrm{M}$ ( \pm )2-amino-5-phosphonopentanoic acid (to block NMDA receptors) to the bath. Action-potential independent miniature IPSCs (mIPSCs) were recorded under the same conditions, but in the presence of $1 \mu \mathrm{M}$ tetrodotoxin (TTX; Sigma) to block sodium channels. Synaptic stimulation of evoked IPSCs (eIPSCs) occurred every $30 \mathrm{~s}$ through a bipolar stimulation electrode positioned within $200 \mu \mathrm{m}$ of the soma. Under baseline conditions the input-output curves for evoked IPSCs did not differ between the two experimental groups (ie, cocaine- or saline-injected rats; Supplementary Figure S1). In current-clamp recordings, series of hyperpolarizing and depolarizing current steps $(500 \mathrm{~ms}$ duration; $10-30 \mathrm{pA}$ increments at $0.3 \mathrm{~Hz}$ ) were delivered from resting membrane potential to evoke subthreshold responses and spike firing. Intrinsic membrane properties and the evoked firing pattern were used to distinguish subtypes of GABAergic interneurons. To determine the changes in neuronal excitability following pharmacological manipulations the series of current pulses was repeated every $3 \mathrm{~min}$ for the duration of the experiment. Comparisons of changes in the number of evoked spikes were made at a current level that reliably produced repetitive firing under controlled conditions. In both voltage-clamp and current-clamp recordings, access resistance was continuously monitored by applying small hyperpolarizing or depolarizing current steps through the recording pipette at the beginning of the sweep, and cells that changed more than $20 \%$ during the recording were excluded from analysis. The morphology of nonpyramidal cells was verified at the end of the experiment using confocal imaging of Alexa 594. After collection of baseline data, DA or specific DA-receptor agonists were bath-applied for 2-3 min. We used the agonist $( \pm)$-quinpirole dihydrochloride to activate D2-like receptors and ( \pm )-6-chloroPB hydrobromide (SKF-81297) to activate D1-like receptors. When the effects of DA antagonists were examined, the D1 antagonist R-[ + ]-7-chloro-8-hydroxy-3-methyl-1-phenyl2,3,4,5-tetrahydro-1H-3-benzazepine (SCH23390) or the D2 antagonist $( \pm)$-sulpiride were bath-applied at least 10 min before application of DA and continued to be present throughout the remainder of the experiment. All DAergic agents were obtained from Sigma. The frequency and amplitude of IPSCs were measured using MiniAnalysis (Synaptosoft, Decatur, GA, USA). Spontaneous or miniature events were detected when they crossed a threshold set at two times the RMS baseline noise. The detected events were confirmed as synaptic events by eye. For sIPSCs and mIPSCs we collected $9 \mathrm{~s}$ long sweeps every $30 \mathrm{~s}$. Two sweeps (representing $1 \mathrm{~min}$ ) were averaged and changes in the amplitude of eIPSCs or the frequency of sIPSCs were plotted over time. For statistical comparisons, the number of evoked responses or spontaneous events was averaged across two separate $5 \mathrm{~min}$ intervals as indicated in the Results section and compared with baseline values. For statistical comparisons in current-clamp recordings, at least 3-5 responses under baseline and drug condition were averaged and compared. Comparisons were performed using two-tailed, paired $t$-tests, unless indicated otherwise. Differences of alpha $\leqslant 0.05$ were considered statistically significant. All data are presented as mean \pm SEM.

\section{RESULTS}

DA has a temporally biphasic effect on the amplitude of eIPSCs in saline-treated animals. Figure 1a shows the effect of a high dose $(20 \mu \mathrm{M})$ of DA on isolated eIPSCs in pyramidal neurons. On average, DA modulated eIPSC amplitude in a biphasic, time-dependent manner, producing an initial decrease (2-20 min after application), followed by a prolonged increase in the amplitude of the eIPSC. To quantify this effect, we averaged the responses over 5 min periods either briefly after DA bath application ('early DA', between 5-10 min after DA was first perfused into the bath) or at a later time point when the increase in eIPSC amplitude had reached a plateau ('late DA', between 25-30 min after DA application). In this and all following experiments, the averaged responses from these time periods were then compared with the averaged response of the baseline period before drug application. As seen in Figure 1a, in saline-treated rats, $20 \mu \mathrm{M}$ DA reduced the amplitude of the eIPSC during the 'early DA' period by about $-24.4 \pm 14.2 \%(p<0.01 ; n=8)$ and increased the eIPSC amplitude during the 'late DA' period on average by $+64.2 \pm 29.7 \%(p<0.05)$. In contrast, in cocaine-treated animals, the initial reduction in eIPSC amplitude was absent and instead an immediate increase of eIPSC amplitude was observed during the early phase of the DA effect $(+30.1 \pm 10.6 \% ; p<0.05)$ that persisted through the late phase of the DA effect ( $+51.1 \pm 23.6 \%$; $p<0.05 ; n=7$; Figure $1 \mathrm{~b})$.

\section{Receptor-Specific Modulation of Evoked IPSCs}

The biphasic modulation of eIPSCs in our adult salinetreated animals is consistent with previous observations in young drug-naïve animals. In these studies, concentrations of extracellular DA, high enough to activate both receptor subtypes in the PFC ( $>1 \mu \mathrm{M} \mathrm{DA})$, lead to a long-lasting enhancement of eIPSCs by activation of D1Rs, whereas the initial reduction in eIPSC amplitude required activation of D2Rs (Seamans et al, 2001; Trantham-Davidson et al, 2004). Accordingly, we found that in saline-treated animals, bath application of the D2R agonist quinpirole $(5 \mu \mathrm{M}, n=6)$ reduced the amplitude of the eIPSC during the period of the early measurement (5-10 min after drug application), which partly recovered by the time of the second late measurement (25-30 min after drug application; quinpirole early $-37.7 \pm 16.4 \%, \quad p<0.01$, quinpirole late $-23.4 \pm 24.7 \%$; $p<0.01 ; n=6$, Figure 2a). Similar results were also observed when DA $(20 \mu \mathrm{M})$ was applied in the presence of the D1 antagonist SCH-23390 (10 $\mu \mathrm{M}, n=3$; data not shown). In contrast, in cocaine-sensitized animals bath application of the selective D2 agonist quinpirole $(5 \mu \mathrm{M})$ failed to induce a reduction in eIPSC amplitude (Figure 2b). Quinpirole did not significantly affect eIPSCs at either the early or late time point (quinpirole early $+0.7 \pm 10 \%$; quinpirole late $-12.3 \pm 8 \% ; n=11)$. On the other hand, D1R-dependent signaling seemed to be unaffected in cocaine-sensitized animals, resulting in increased eIPSC amplitudes. Using different approaches to stimulate D1Rs, this effect consistently became significant by the time of the second late measurement (Figure 2c-e). Bath application of the selective D1R agonist SKF-81297 $(5 \mu \mathrm{M} ; n=6)$ increased eIPSC amplitude by $31.4 \pm 22 \%(p>0.05)$ during the period of 

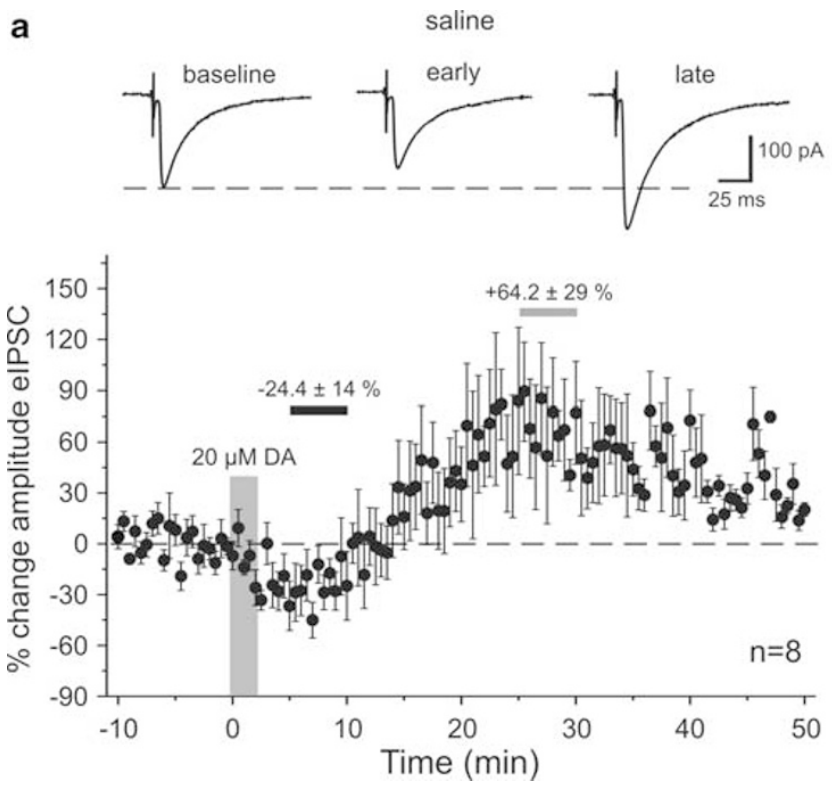

b

\section{cocaine}
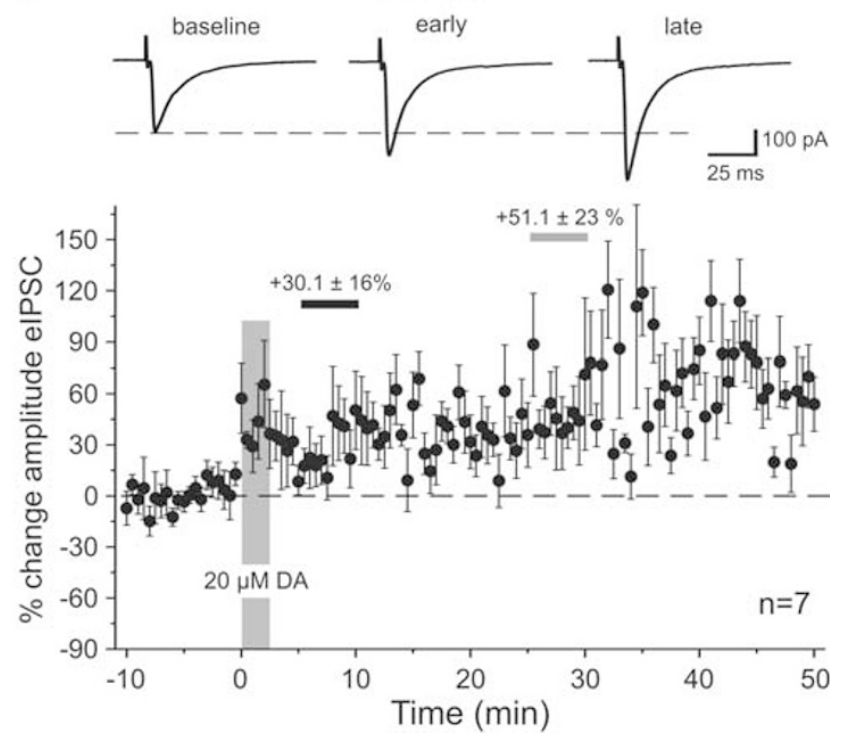

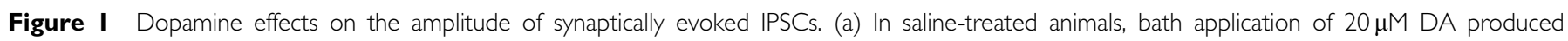

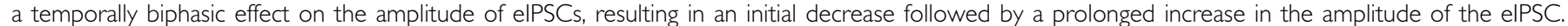

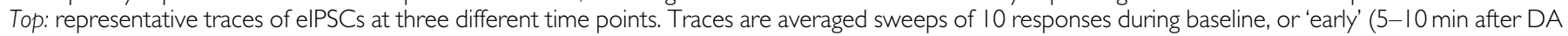

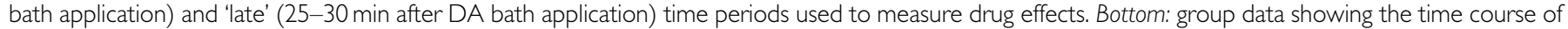

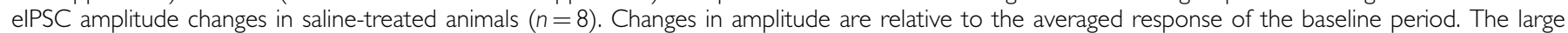
vertical bar indicates the duration of DA application. Small horizontal bars indicate the periods from which averaged measures were used for statistical

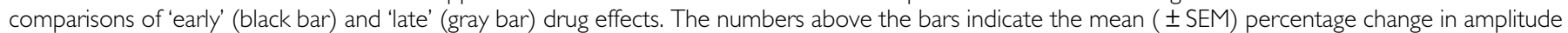

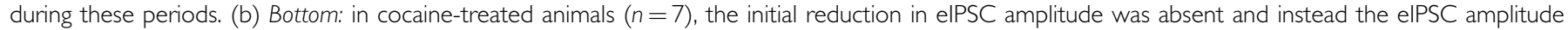
showed a rapid and persistent increase. Top: Representative traces of elPSCs for the same time periods as indicated in (a).

the early measurement, and by $85.7 \pm 30 \%(p<0.05)$ during the period of the late measurement. Similarly, application of $20 \mu \mathrm{M}$ DA in the presence of the selective D2R antagonist sulpiride $(5 \mu \mathrm{M})$ increased eIPSC amplitudes by $27.9 \pm 18 \%$ $(p>0.05)$ during the early measurement and by $26.0 \pm 5 \%$ $(p<0.01 ; n=11)$ during the period of the late measurement. Finally, a low dose (100 nM) of DA by itself, which previously had been shown to predominantly activate D1Rs under similar recording conditions in drug-naïve animals (Trantham-Davidson et al, 2004), also increased eIPSC amplitudes in cocaine-sensitized rats (Figure 2e; early DA + 20.9 $\pm 12.6, p>0.05$; late DA $+33.7 \pm 11.3, p=0.5 ; n=8$ ). Taken together, these results suggest that in cocaine-sensitized animals D2 mediated modulation of IPSCs is compromised, but D1R-dependent mechanisms are unaffected.

\section{DA Modulation of Spontaneous IPSCs}

In a first effort to assess which components of synaptic transmission are altered in cocaine-sensitized animals, we analyzed the frequency and amplitude distribution of sIPSCs in saline- and cocaine-treated animals (Figure 3). Our results show that in slices from both groups of animals bath application of a high dose of DA $(20 \mu \mathrm{M})$ led to a significant increase in the frequency of sIPSCs. The development of this effect over time was noticeably different in saline- and cocaine-treated animals. Figure $3 b$ and $c$, show the time-course of the change in sIPSC frequency and the relative changes in the amplitude distribution of sIPSCs between 5-10 min and 25-30 min after DA bath application, respectively, compared with baseline measures. In slices from saline-treated animals, the frequency of sIPSCs gradually increasaed and reached a plateau value after about $20 \mathrm{~min}$ (Figure $3 \mathrm{~b}$; early DA $+15.4 \pm 6 \%, p>0.05$; late $\mathrm{DA}+29.0 \pm 12 \%, p<0.05 ; n=8)$. We plotted changes in the frequency distribution of sIPSC amplitudes to see whether DA might selectively modulate sIPSCs of a certain size (Figure 3b, right column). We found that DA consistently increased the frequency of events of all amplitudes, with the exception of very small events $(<10 \mathrm{pA})$ that were decreased during the period of the early DA effect. However, across all events within a measurement period the DA-induced increase in sIPSC frequency had no effect on mean sIPSC amplitude (Figure $3 \mathrm{~b}$ inset). In cocaine-sensitized animals (Figure 3c), the frequency of sIPSCs increased rapidly after DA application and remained significantly elevated throughout the time of the recordings (early DA + $44.7 \pm 13 \%, p=0.05$; late DA $+24.9 \pm 7 \%, p<0.05 ; n=6)$. As in saline animals, the mean amplitude of sIPSCs did not significantly change during any of the three measurement periods (Figure $3 \mathrm{c}$ inset), but unlike in slices from saline animals, there occurred no reduction in small amplitude events during the early measurement of DA effects in cocaine-treated animals. Instead, there was a disproportional increase in the number of large amplitude $(>70 \mathrm{pA})$ events (Figure 3, right column). One potential mechanism for the differential DA modulation of small and large amplitude IPSCs in saline- and cocaine-treated animals was explored in a series of action potential-independent miniature IPSC recordings (see below).

The increase in sIPSC frequency seen in cocainesensitized animals in response to $20 \mu \mathrm{M}$ DA depended 

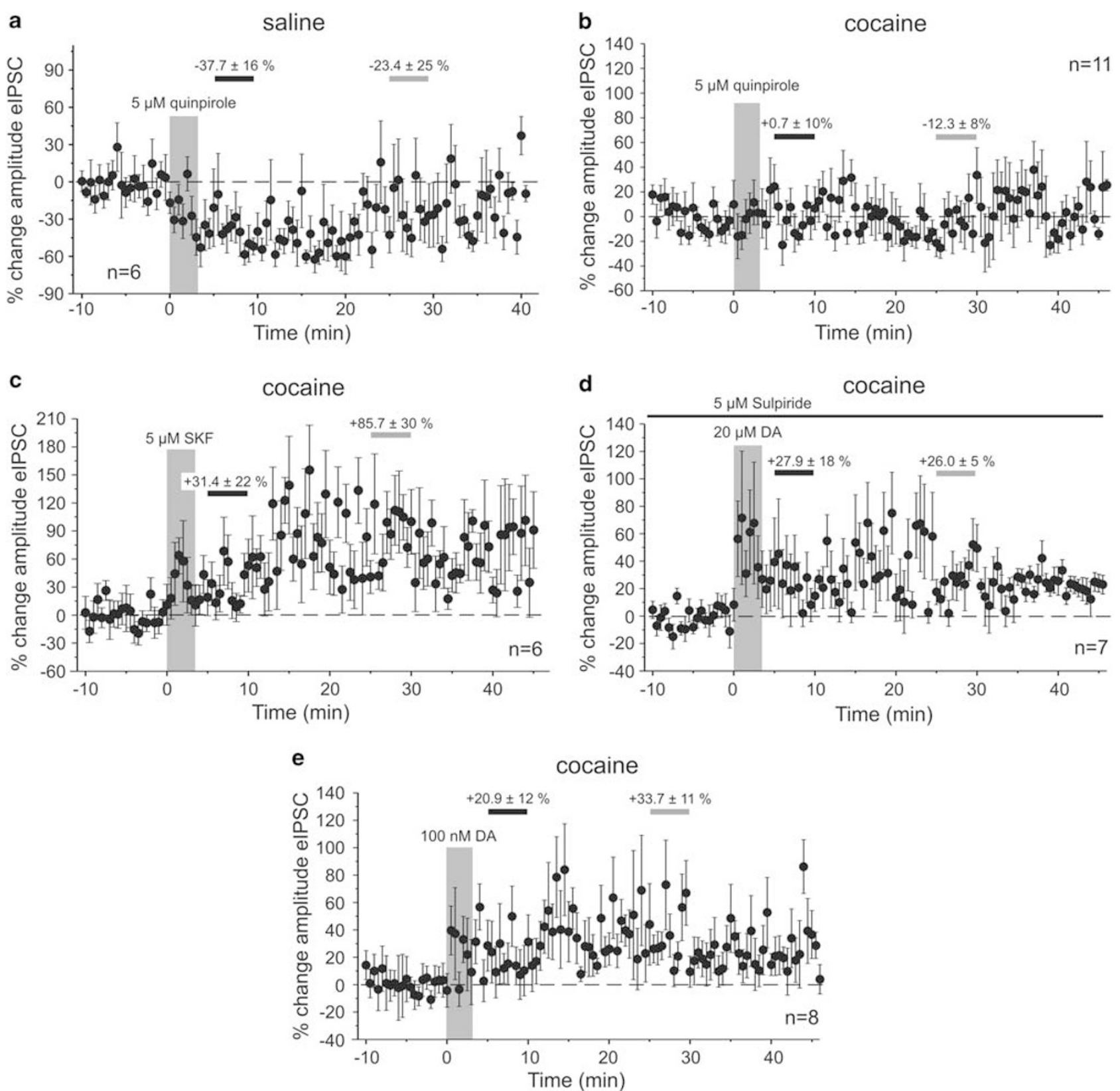

Figure 2 Pharmacology of DA effects on elPSCs in saline-treated and cocaine-sensitized animals. (a) Bath application of the D2-type receptor agonist quinpirole $(5 \mu \mathrm{M})$ induced a rapid reduction in elPSC amplitude in saline-treated animals. The graph shows the time course of elPSC amplitude changes relative to the averaged response of the baseline period. In all graphs, the large vertical bar indicates the period of drug application. Horizontal bars indicate the periods from which averaged measures were used for statistical comparisons of 'early' (black) and 'late' (gray) drug effects, and the numbers indicate the mean ( \pm SEM) percentage change in amplitude during these 5 min periods. (b) Activation of D2-type receptors in cocaine-treated animals $(n=I \mathrm{I})$ failed to induce a similar reduction in eIPSC amplitude as seen in saline animals. The differential responses to quinpirole in the two treatment groups parallel the effects of DA on the transient reduction in elPSCs amplitude in saline- and cocaine-treated animals, respectively. (c, d) In contrast to D2 receptor activation, DI receptor activation is unaltered in cocaine-treated rats. Bath application of the DI agonist SKF-8I297 (c) or of DA (20 $\mu$ M) in the presence of the D2 receptor antagonist sulpiride (d) evoked a rapid and persistent increase in the amplitude of the elPSCs $(n=7)$. Sulpiride was present in the bath for the duration of the recording (black line). (e) Bath application of a low dose (100 nM) of DA also results in an immediate and long-lasting increase in elPSC amplitude. Low concentrations of DA $(<\mid \mu M)$ were previously reported to preferentially activate DI receptors (Trantham-Davidson et al, 2004). See text for details.

on D1R activation, as similar increases were seen in response to SKF-81297 ( $5 \mu \mathrm{M} ; n=6)$. SKF-81297 increased the frequency of sIPSCs by $23.1 \pm 4 \% \quad(p<0.01 ; n=6)$ during the early measurement and by $36.0 \pm 11 \%$ $(p<0.05 ; n=6)$ during the period of the late measurement (Figure $4 \mathrm{c}$ and $\mathrm{d}$ ), and this again was mimicked by the application of a low dose of DA (Figure $4 \mathrm{~d}$ ). In contrast, D2-receptor activation with $5 \mu \mathrm{M}$ quinpirole (Figure $4 \mathrm{a}, \mathrm{b}$ and $\mathrm{d}$ ) decreased the number of sIPSCs in saline-treated animals (early quinpirole $-15.6 \pm 7 \%$, $p>0.05$; late quinpirole $-32.7 \pm 7 \%, p<0.05, n=8)$, but had no consistent effect in slices from cocaine-treated 
a

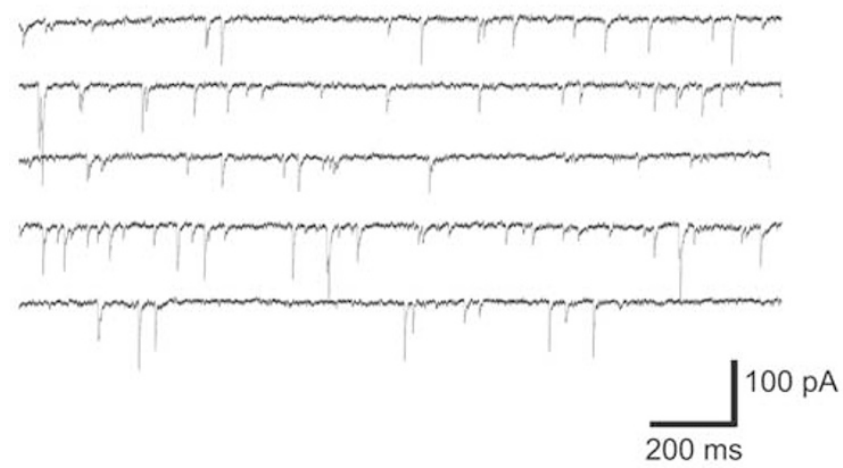

\section{$20 \mu \mathrm{M}$ DA}

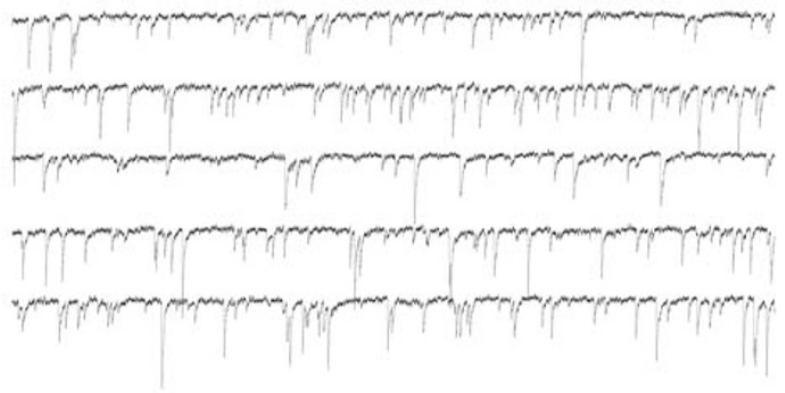

$20 \mu \mathrm{M}$ bicuculline b

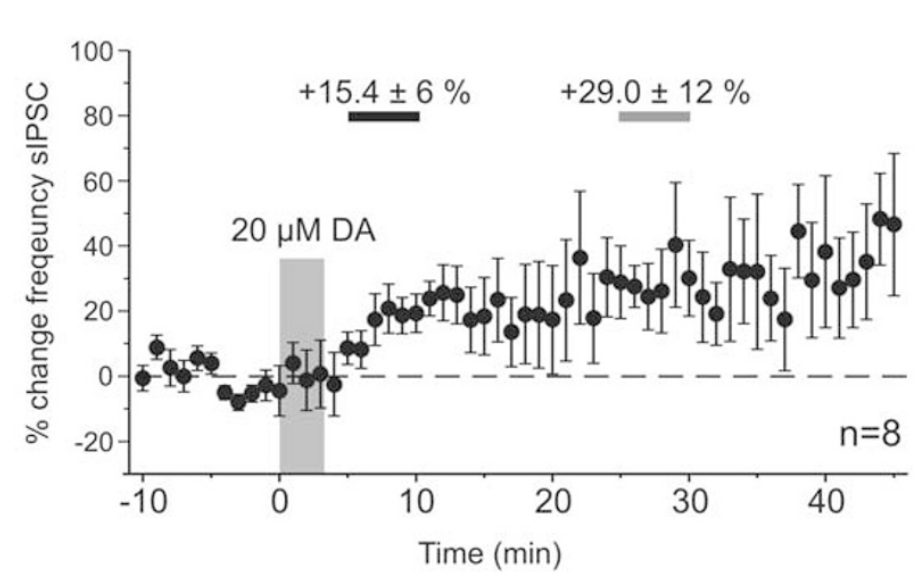

c

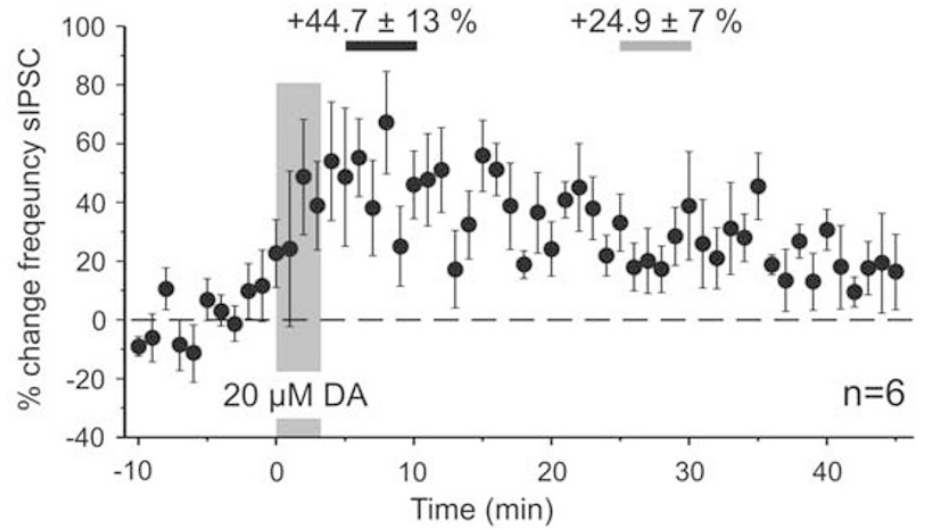

saline

cocaine

Time $(\mathrm{min})$
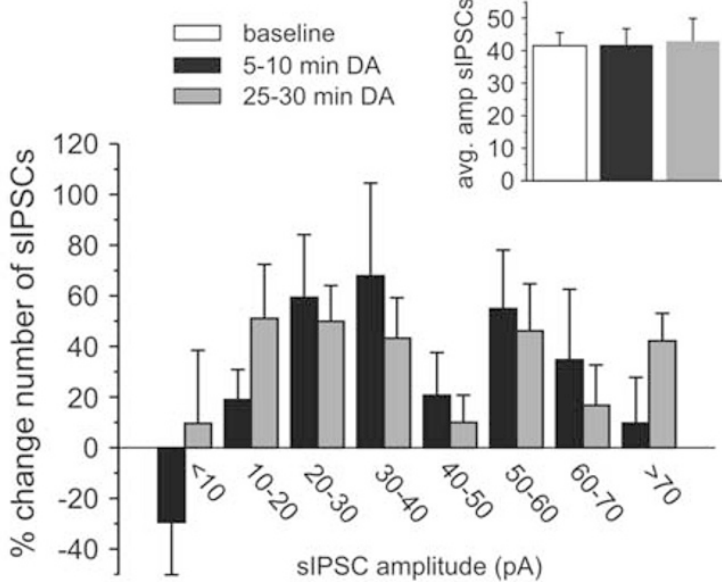

sIPSC amplitude (pA)

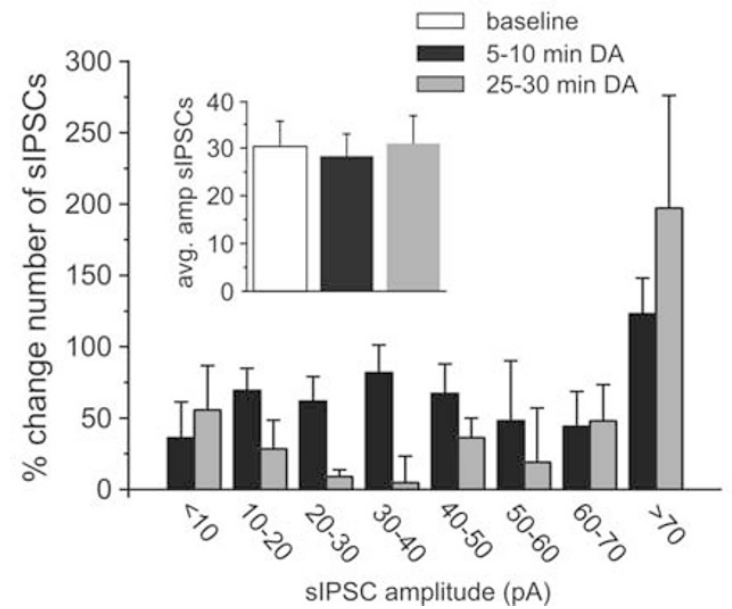

Figure 3 Dopamine modulation of spontaneous IPSCs in saline- and cocaine-treated animals. (a) Example traces showing voltage-clamp recordings of pharmacologically isolated sIPSCs from PFC pyramidal cells under baseline conditions (left column) and after application of $20 \mu$ M DA. Most synaptic events were blocked by bath application of the GABA antagonist bicuculline $(20 \mu \mathrm{M})$ at the end of the experiments. Both in saline- and cocaine-treated animals, DA led to an increase in the frequency of sIPSCs, albeit with different time courses (b, c). (b) Time course and amplitude histograms of the effect of $20 \mu M$ DA on sIPSCs in saline-treated animals $(n=8)$. Left: The graph shows minute-by-minute changes in the frequency of sIPSCs compared with the baseline average. The frequency increase slowly and reached a relatively stable level after about $20 \mathrm{~min}$. The periods of measurement of early (5-10 min, light gray) and late (25-30 min, dark gray) DA effects are indicated by horizontal bars. The increase in the average frequency of sIPSCs was significant for the late measurement $(p<0.05)$. Right: Plotting the relative change in the number of sIPSCs across a range of amplitudes (I0 pA bins) revealed that DA consistently increased events of all amplitudes with the exception of very small events $(<10 \mathrm{pA})$, which showed a decrease in frequency during the period of the early DA effect. Inset: changes in the overall frequency and the relative distribution of sIPSCs did not affect the amplitude of the average sIPSC. (c) Time course and amplitude histograms of the effect of $20 \mu \mathrm{M}$ DA on sIPSCs in cocaine-treated animals $(n=6)$. Left: in cocaine-treated animals, the frequency of sIPSCs rapidly increased. The increase in the average frequency of sIPSCs was significant at both the early and late measurement $(p<0.05)$. Right: plotting the relative change in the number of sIPSCs across a range of amplitudes showed a consistent increase of events across all amplitudes following DA application. Inset: similar to the effects in saline animals, any shift in the relative distribution of events was not large enough to affect the average sIPSC amplitude. 

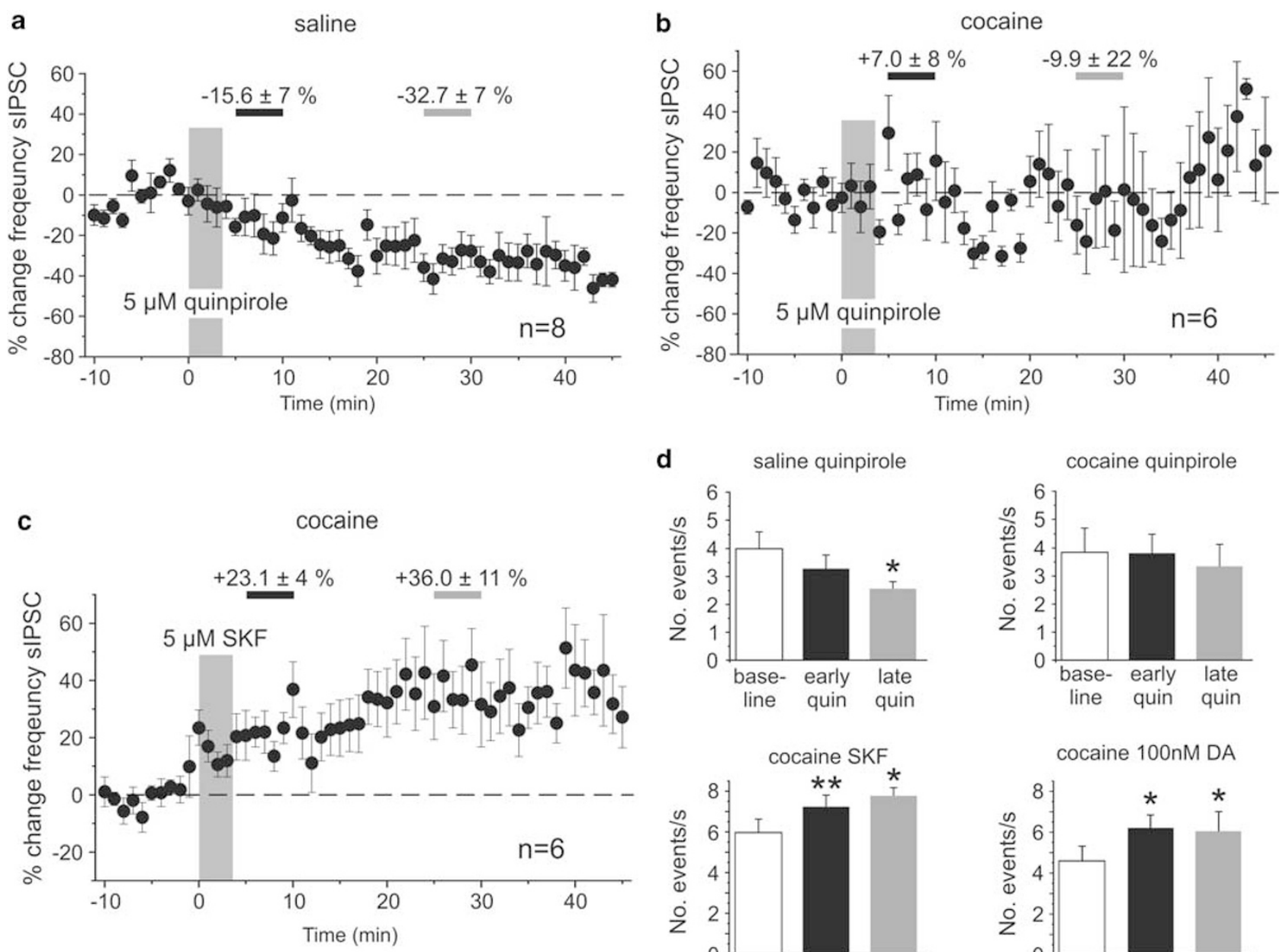

d
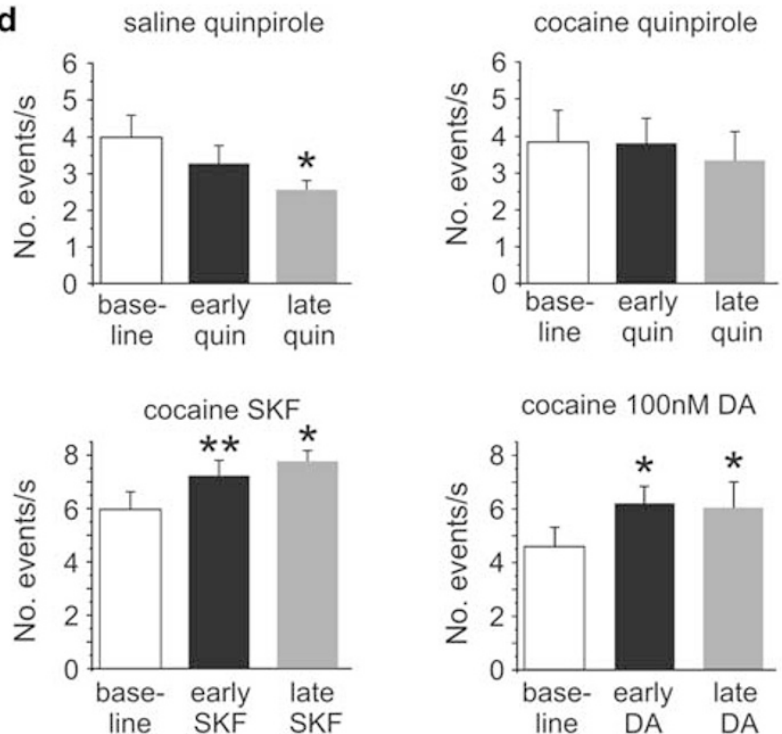

Figure 4 Pharmacology of dopamine modulation of spontaneous IPSCs in saline- and cocaine-treated animals. (a, b) Time course of changes in sIPSC frequency following D2 receptor stimulation with quinpirole $(5 \mu \mathrm{M})$ in saline- (a) and cocaine-treated (b) animals. In saline animals, $(n=6)$ there was a slowly developing reduction in the number of sIPSCs that became significant by the time of the late measurement period (see $d$ ). In cocaine-treated animals there was no discernible effect of D2 receptor stimulation. (c) In contrast, DI receptor stimulation with SKF-8I 297 produced a rapid and persistent increase in the frequency of sIPSCs in cocaine-treated animals $(n=6)$. Similar increases were seen with bath application of I00 nM DA (see d). (d) Summary graph showing the average changes in sIPSC frequency during the early (5-10 min following drug application) and late (25-30 min following drug application) measurement periods for the data shown in $(a-c)$, as well as results obtained with bath application of $100 \mathrm{nM} D A(n=8$; $* p<0.05$, *** $<<0.0$, paired $t$-tests).

animals (early quinpirole $+7.0 \pm 8 \%, p>0.05$; late quinpirole $-9.9 \pm 22 \%, p>0.05 ; n=6)$.

\section{DA and D2R-Dependent Modulation of Miniature IPSCs}

sIPSCs represent both action potential-dependent and -independent release of GABA. In contrast, miniature IPSCs (mIPSCs) are recorded in the presence of TTX $(1 \mu \mathrm{M})$ to eliminate the contribution of action potential-mediated release events. Changes in GABAergic release could also contribute to the D2R-dependent reduction in eIPSC amplitude and the lack thereof in cocaine-sensitized animals. We therefore, studied the effects of DA and D2R stimulation on mIPSCs to determine whether the increase in the frequency of sIPSCs was due to a selective effect on interneuron excitability and spike firing, or reflected at least in part a modification of GABA release as measured with mIPSCs. mIPSCs were recorded in the presence of TTX $(1 \mu \mathrm{M})$ and changes in the frequency of mIPSCs were compared between cocaine- and saline-treated animals (Figure 5). In saline animals, quinpirole $(5 \mu \mathrm{M})$ significantly reduced the number of mIPSCs $5-10 \mathrm{~min}$ after drug application (Figure $5 \mathrm{a} ;-13.3 \pm 6 \% ; p<0.05 ; n=7$ ). DA $\mathrm{D} 2 \mathrm{R}$ activation not only reduced the frequency, but also the average amplitude of mIPSCs, suggesting the presence of an additional post-synaptic mechanism, through which DA can modulate inhibitory post-synaptic currents (IPSCs; Seamans et al., 2001). Quinpirole-induced changes in mIPSC frequency and amplitude occurred independent of changes in access resistance.

In cocaine-sensitized rats, a similar change in the number of events was not observed at any time of the recording (Figure $5 b ;-0.7 \pm 9 \% ; p>0.05 ; n=7$ ). Bath application of the full agonist DA $(20 \mu \mathrm{M})$ led to a significant increase in the frequency of mIPSCs in slices from cocaine-sensitized animals (Figure 5d; baseline $4.7 \pm 0.4$ events/s, DA early $6.3 \pm 0.5$ events/s; $p<0.01 ; \quad$ DA late $6.7 \pm 1.0$ events $/ \mathrm{s}$ $p \leqslant 0.05 ; n=7$ ), but only a moderate increase in slices from 
a

saline

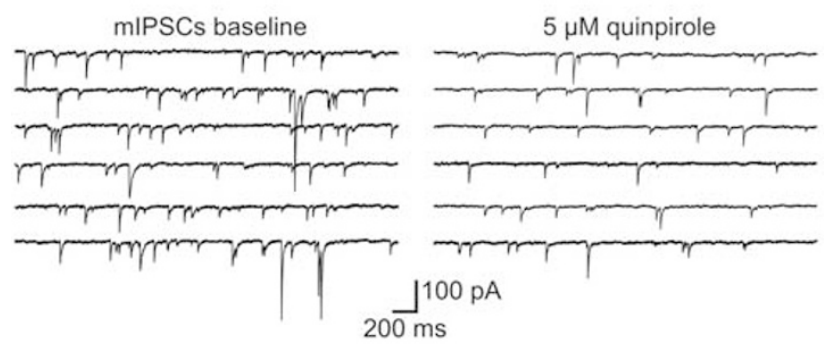

a2

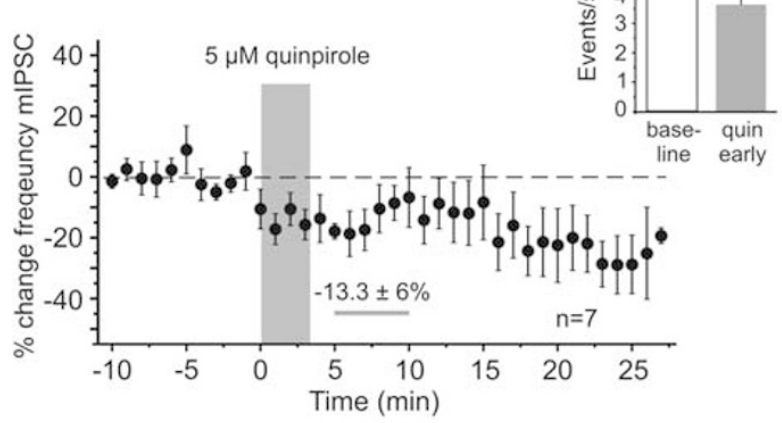

a3

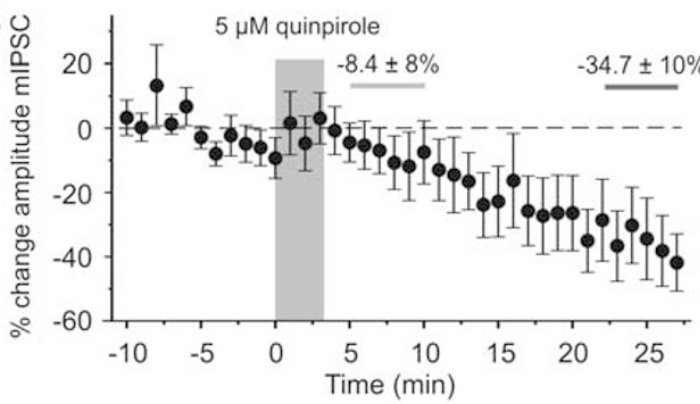

c

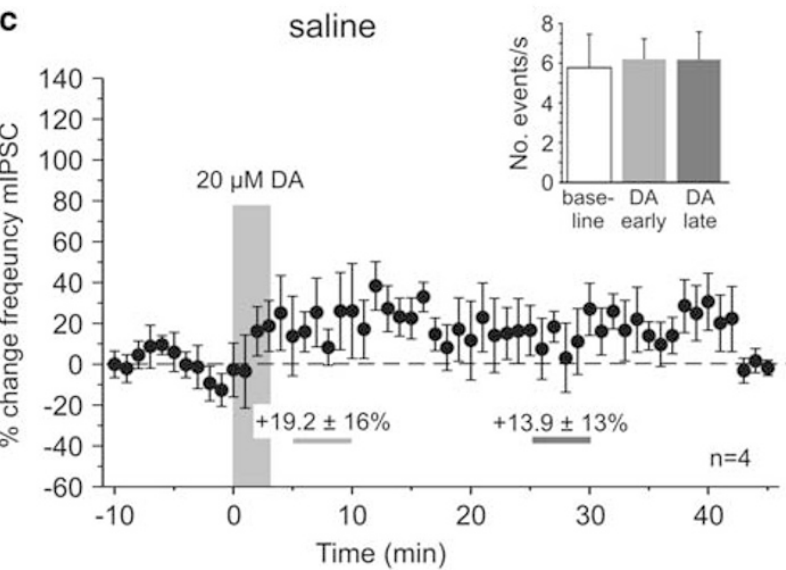

b

cocaine
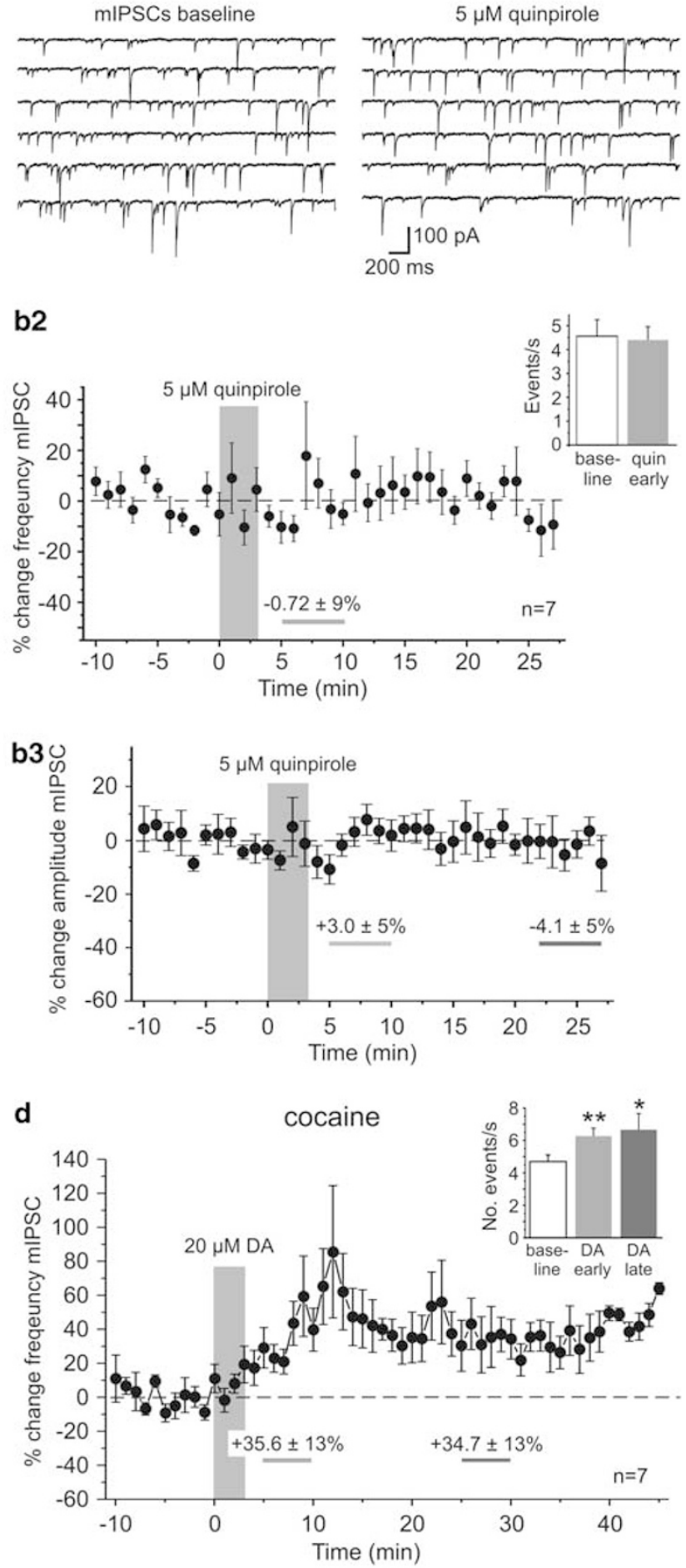

Figure 5 Dopamine and D2 receptor-dependent modulation of action potential independent miniature IPSCs in saline- and cocaine-treated animals. (a) In saline-treated animals, $(n=7)$ quinpirole $(5 \mu \mathrm{M})$ significantly reduced the frequency and the average amplitude of mIPSCs. Top: representative traces showing voltage-clamp recordings of mIPSCs in PFC pyramidal cells before (left column) and after quinpirole application. (a2) Time course of quinpirole effects on the frequency of mIPSCs. The inset shows a comparison of the average frequency of events from all cells during baseline and 5-10 min after quinpirole application. (a3) Time course of quinpirole effects on the average amplitude of mIPSCs. The reduction in mIPSC amplitude became significant during the end of our recordings ( $23-27$ min post-quinpirole application; $-34.7 \pm 10 \% ; p<0.05$ ) before experiments were terminated by the experimenter. (b) In cocaine-treated animals $(n=7)$, quinpirole did not consistently change the frequency or amplitude of mIPSCs. Top: representative traces showing voltage clamp recordings of mIPSCs before (left column) and after quinpirole application. (b2) Time course of quinpirole effects and average frequency of events from all cells during baseline and 5-10 min after quinpirole application (inset). (b3) Time course of quinpirole effects on average mIPSC amplitude. (c, d) Activation of both DI and D2 receptors with the full agonist DA $(20 \mu \mathrm{M})$ did not significantly change the frequency of mIPSCs in saline-treated animals $(c, n=4)$, but as shown in (d) led to a significant increase in the number of mIPSCs in cocaine-sensitized animals $(n=7$; $*<<0.05$, *** $p<0.01$, paired $t$-tests). 
saline-treated animals (Figure $5 \mathrm{c}$; baseline $5.8 \pm 0.4$ events/s, DA early $6.2 \pm 1.7$ events/s; $p>0.05$ early; DA late $6.2 \pm 1.4$ events/s $p>0.05 ; n=4)$. This DA-induced increase in the frequency of mIPSCs, together with the absence of an effect of quinpirole on sIPSCs, suggests that a D1R-dependent increase in GABA release contributes to the rapid increase in the number of sIPSCs described above (c.f. Figure 3), but that in normal animals this is counteracted by a D2mediated reduction in release. Thus, taken together, the data from sIPSC and mIPSC recordings suggest that in control animals opposing D1/D2 mechanisms determine the direction and time course of DA modulation of inhibition, and that both D2R-dependent reduction in GABA release and the desensitization of post-synaptic GABA receptors could contribute to the reduction of eIPSCs. In contrast, in cocaine-sensitized animals, the efficacy of D2R stimulation seems to be greatly reduced, resulting in a change in the time course of DA modulation of IPSCs and enhanced inhibition by D1-dependent mechanisms, most likely because of parallel increases in the frequency of action potential-dependent and -independent synaptic events.

\section{Cocaine-Sensitization Reduces D2R-Dependent Modulation of Action-Potential Firing in PFC Interneurons}

Recently, it was shown that in PFC interneurons from adult drug-naïve animals, D2R activation can increase actionpotential firing evoked by somatic current injection (Tseng and O'Donnell, 2007). Therefore, we examined whether withdrawal from cocaine can potentially also affect cortical inhibition by D2-dependent modulation of spike firing in interneurons. To this end, we obtained current-clamp recordings from identified nonpyramidal neurons in the PFC (Figure 6a) and we examined changes in membrane excitability in response to D2R activation with quinpirole. On the basis of their firing pattern, afterhyperpolarization (AHP), and spike frequency adaptation characteristics (Cauli et al, 1997; Kroener et al, 2007), cells were classified either as fast-spiking interneurons (FS; $n=14$ ) or nonfastspiking cells (NFS; $n=12$; Figure 6). Fast-spiking cells were characterized by action potentials of short duration, which were followed by fast, monophasic AHPs of large amplitude (Table 1). Fast-spiking cells were able to sustain high steady-state firing frequencies with relatively little

Figure 6 D2 receptor-dependent modulation of current-evoked action potential firing in interneurons from saline- and cocaine-treated animals. (a) Examples of fast-spiking (FS) and non-fast spiking (NFS) interneurons recorded in the prelimbic cortex of adult rats. Cells were filled with Alexa 594 during whole-cell recording and reconstructed using z-stacked confocal images. Scale bar is $50 \mu \mathrm{m}$. (b) Example sweeps showing that D2 receptor stimulation with quinpirole $(5 \mu \mathrm{M})$ increases the action-potential firing evoked by somatic current injection in both NFS and FS cells from salinetreated animals (left column), but not from cocaine-treated animals. Scale bars represent $200 \mathrm{~ms}$ and $20 \mathrm{mV}$. (c) Summary plot for the effects of quinpirole on evoked spike firing in FS cells (open symbols) and NFS cells (gray squares) in saline- and cocaine-treated animals. Individual values for each cell are averages of at least three repetitions for baseline and quinpirole condition. (d) Same data as in (c) plotted to show the average change in the number of action potentials for FS and NFS cells in saline- and cocaine-treated animals ( ${ }^{*} p<0.05$ paired $t$-tests). spike-frequency adaptation (Figure 5b). Non-fast spiking cells showed conspicuous spike frequency adaptation (Figure 6b), and their spike kinetics and AHP amplitude were significantly different from that of FS cells both in
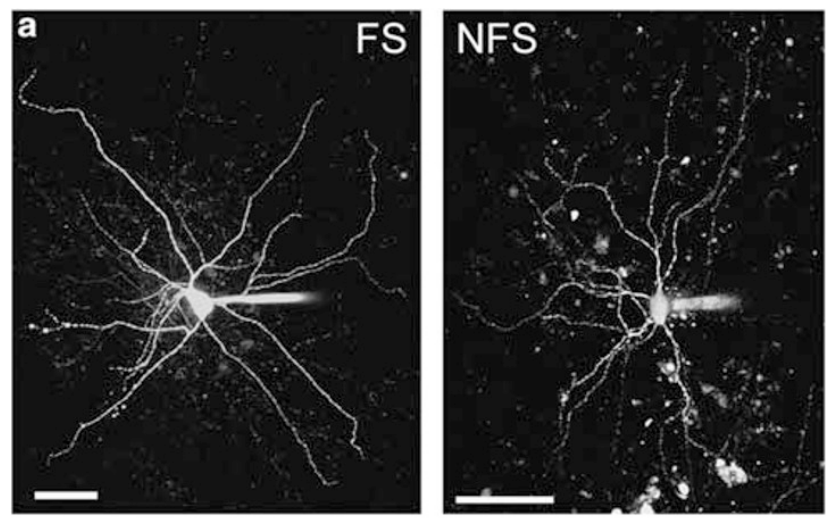

b

baseline quine
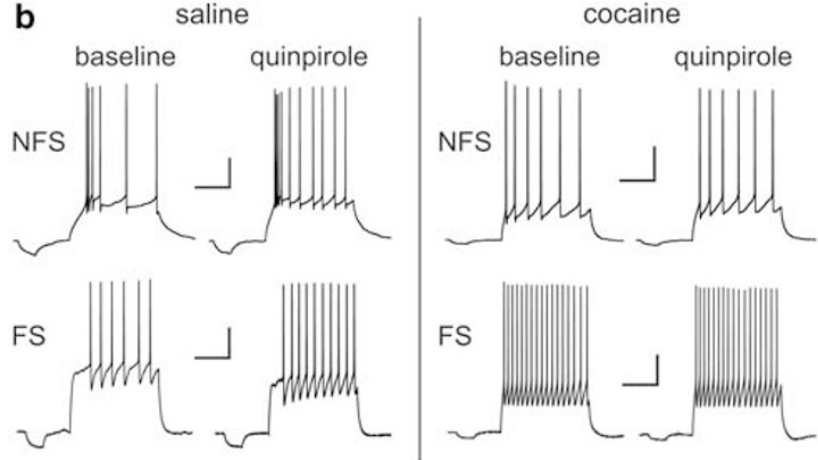

C
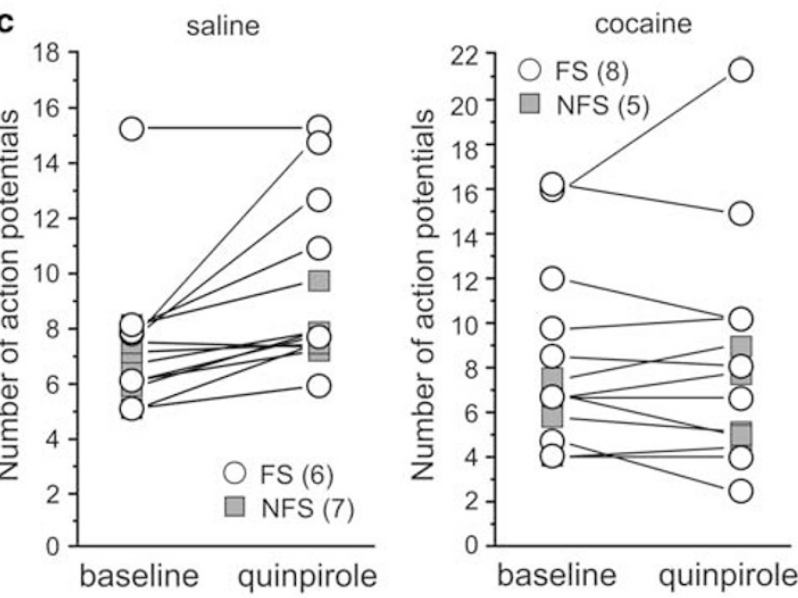

d
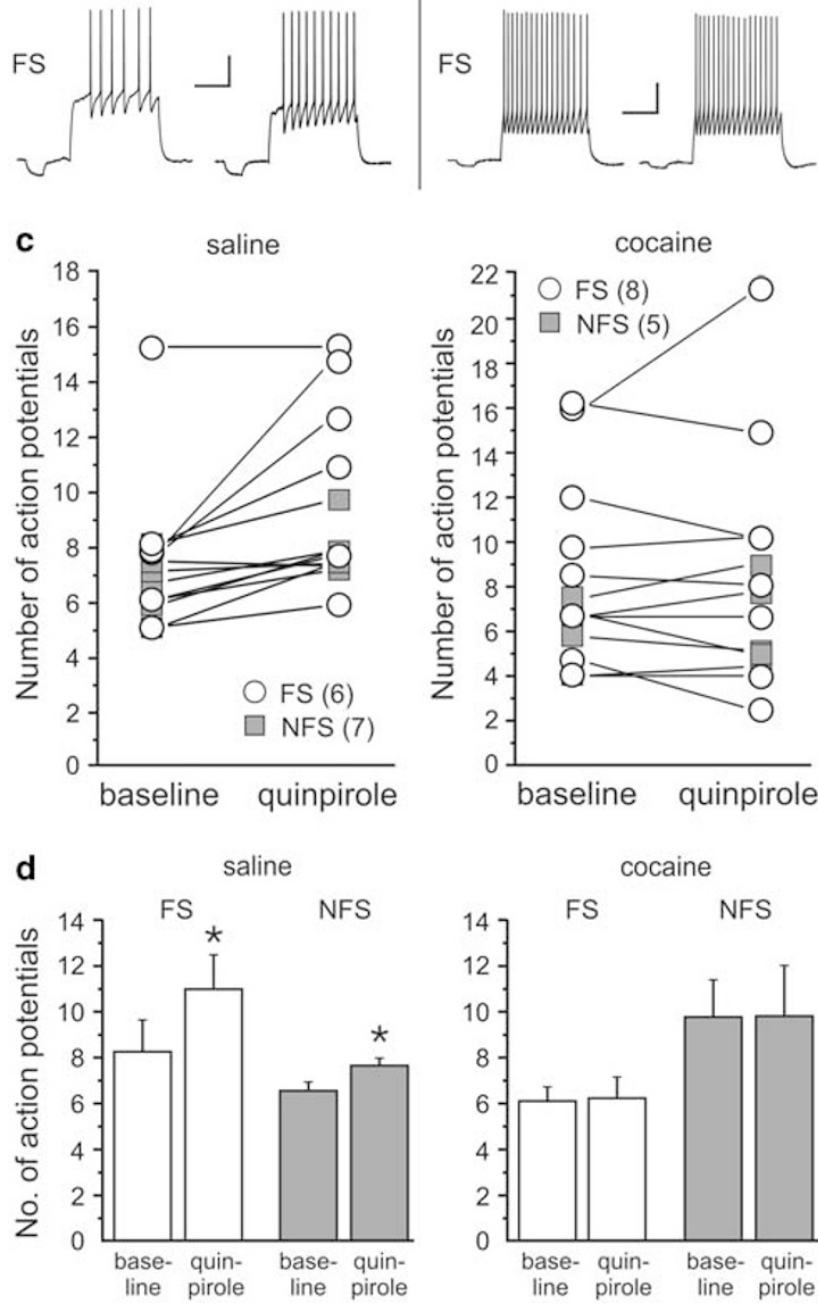
Table I Electrophysiological Properties of 3 Classes of Neurons in Layers 5/6 of Rat Prefrontal Cortex from Saline- and Cocaine-Treated Animals (Means \pm SEM)

\begin{tabular}{|c|c|c|c|c|c|c|c|}
\hline & \multicolumn{2}{|c|}{ Saline } & \multicolumn{2}{|c|}{ Cocaine } & \multirow{2}{*}{$\begin{array}{c}\text { Saline } \\
\text { Pyramidal } \\
(n=13)\end{array}$} & \multicolumn{2}{|r|}{ Cocaine } \\
\hline & $\begin{array}{c}\text { FS } \\
(n=6)\end{array}$ & $\begin{array}{c}\text { NFS } \\
(n=7)\end{array}$ & $\begin{array}{c}\text { FS } \\
(n=8)\end{array}$ & $\begin{array}{c}\text { NFS } \\
(n=5)\end{array}$ & & $\begin{array}{l}\text { Pyramidal } \\
(n=6)\end{array}$ & $\begin{array}{l}\text { Significant } \\
\text { differences }\end{array}$ \\
\hline Input resistance (MegaOhm) & $223.4 \pm 34.7$ & $262.7 \pm 66.6$ & $202.6 \pm 29.0$ & $241.6 \pm 29.3$ & $123.9 \pm 13.5$ & $162 \pm 35.6$ & - \\
\hline Rheobase current (pA) & $145.0 \pm 32.6$ & $94.3 \pm 20.2$ & $142.5 \pm 30.3$ & $109.0 \pm 13.9$ & $137.6 \pm 12.0$ & $115 \pm 11.2$ & - \\
\hline AP threshold $(\mathrm{mV})$ & $-39.9 \pm 2.3$ & $-44.6 \pm 1.0$ & $-40.7 \pm 1.2$ & $-40.4 \pm 1.5$ & $-41.9 \pm 1.1$ & $-42.3 \pm 1.3$ & - \\
\hline AHP amplitude (mV) & $17.4 \pm 1.17$ & $7.2 \pm 1.16$ & $19.7 \pm 1.16$ & $7.5 \pm 1.4$ & $6.5 \pm 1.09$ & $6.7 \pm 1.05$ & SAL: FS > NFS*** COC: FS > NFS*** \\
\hline
\end{tabular}

Abbreviations: AHP, afterhyperpolarization; AP, action potential; FS, fast-spiking cells; NFS, non-fast-spiking cells.

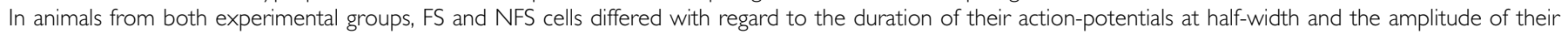

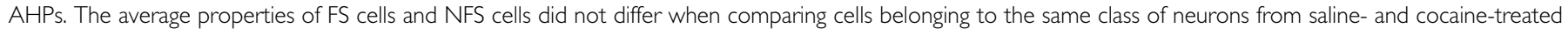
animals. Significant differences indicated by the use of Students $t$-tests $(* * p<0.0 \mathrm{I})$.

tissue from saline-treated and cocaine-treated animals (Table 1). No differences in basic membrane properties were observed when comparing cells belonging to the same class in saline-treated or cocaine-treated rats. However, both FS and NFS cells showed similar differences in their response to quinpirole $(5 \mu \mathrm{M})$ when comparing cells in slices from saline-treated and cocaine-treated animals (Figure $6 \mathrm{c}$ and $\mathrm{d}$ ): In saline animals, quinpirole produced a small but consistent increase in the number of currentevoked spikes in both FS cells (baseline $8.2 \pm 1.4$; quinpirole $11.0 \pm 1.5 ; p<0.05$ ), as well as NFS cells (baseline $6.5 \pm 0.38$; quinpirole $7.6 \pm 0.32 ; p<0.05)$. In contrast, in cocaine animals, quinpirole had no consistent effect on membrane excitability or the number of evoked spikes in either FS or NFS cells (Figure $6 \mathrm{c}$ and d). Taken together, our results suggest that in cocaine-sensitized animals the ability of D2R stimulation to modulate the activity of interneurons and to regulate GABAergic transmission onto pyramidal cells is greatly reduced. In contrast, D1R-dependent mechanisms, which can increase the amplitude of evoked IPSCs and the frequency of spontaneous IPSCs are not affected.

\section{DISCUSSION}

We show that repeated noncontingent exposure and withdrawal from cocaine alter DA modulation of inhibition in the PFC. In control animals, DA and D2R stimulation result in a transient reduction of eIPSCs, which is absent in cocaine-sensitized animals. These changes in eIPSCs are paralleled by a lack of D2R modulation of GABAergic release as measured with mIPSCs, and they manifest in changes in the time course of DA modulation of sIPSCs. In addition, D2R-mediated increases in current-evoked spike firing in interneurons from saline-treated animals were absent in cocaine-sensitized animals. Therefore, the timeand concentration-dependent interplay of D1Rs and D2Rs that characterizes DA modulation in control animals is disrupted in sensitized animals, resulting in an unopposed D1R-mediated increase in GABAergic inhibition. This loss of synergism may alter normal PFC network processing, thus contributing to the functional hypofrontality seen in cocaine addicts.

\section{DA-GABA Interactions in the PFC as Targets for Cocaine-Induced Neuroadaptations}

Numerous studies have shown the importance of prefrontal cortical DA and GABA neurotransmission in the development or reinstatement of addiction to cocaine. Injections of DA receptor antagonists into the PFC prevent, while agonists can induce reinstatement, and DA release in the PFC is increased during reinstatement (Sorg et al, 1997; McFarland and Kalivas, 2001; McFarland et al, 2004; Sun and Rebec, 2005; Williams and Steketee, 2005). Repeated exposure to cocaine decreases D2R function in the PFC, leading to persistent cognitive deficits (Briand et al, 2008). Injections of quinpirole into the mPFC block sensitization (Beyer and Steketee, 2002), while injections of a D2 antagonist enhance motor activity (Steketee and Walsh, 2005). Moreover, non-contingent cocaine administration produces a persistent decrease in D2R-dependent regulation of cortical excitability (Nogueira et al, 2006). GABA in the $\mathrm{PFC}$ is released from local interneurons and projections from the VTA (Carr and Sesack, 2000). GABAergic interneurons are a prominent target of cortical DA innervation (Sesack et al, 1995) and they possess both D1- and D2-type DA receptors (LeMoine and Gaspar 1998; Santana et al, 2009). Local infusion of the $\mathrm{GABA}_{\mathrm{B}}$ agonist baclofen blocks the initiation of cocaine-induced behavioral sensitization (Steketee and Beyer, 2005). Once sensitization is induced, the levels of extracellular GABA in the PFC are increased (Jayaram and Steketee, 2005, 2006), and cue-induced drug-seeking selectively increases the expression of c-Fos in interneurons of the prelimbic cortex, while simultaneously reducing activity in pyramidal cells (Miller and Marshall, 2004).

\section{Mechanisms of DA Modulation of Inhibition in Control- and Cocaine-Sensitized Animals}

Reports on the effects of DA on GABAergic transmission in the PFC of drug-naïve animals, paint a complex and often contradictory picture, and both a reduction (Abekawa et al, 2000; Gonzalez-Islas and Hablitz 2001; Seamans et al, 2001; Gao et al, 2003; Trantham-Davidson et al, 2004) and an increase (Rétaux et al, 1991; Grobin and Deutch, 1998; Zhou and Hablitz 1999; Gulledge and Jaffe, 2001; Seamans et al, 
2001; Gao et al, 2003; Trantham-Davidson et al, 2004, Kroener et al, 2007) in either the amplitude of eIPSCs, the frequency of sIPSCs, or the extracellular levels of GABA as measured with microdialysis have been described, hampering the interpretation of changes seen in cocainesensitized animals.

We found that in adult saline-treated animals DA had time-dependent effects on synaptically evoked IPSCs that were specific for D1R and D2R activation, replicating previous results in young drug-naïve rats (Seamans et al, 2001; Trantham-Davidson et al, 2004). Under normal conditions high DA $(>1 \mu \mathrm{M})$ activates both D1Rs and D2Rs, but the initial D2R-mediated reduction in eIPSC amplitude occludes the prolonged D1R-mediated enhancement (Figure 1; Seamans et al, 2001; Trantham-Davidson et al, 2004). The D2R-dependent reduction in eIPSC amplitude in saline-treated animals could result from alterations in GABA release at the presynaptic terminal, as indicated by a reduction in the frequency of mIPSCs. Surprisingly, in saline-treated animals a high dose of DA did not result in a similar reduction in the frequency of mIPSCs, thus leaving the need for an additional mechanism to explain the transient reduction of eIPSCs in control animals. In young drug naïve animals, D2R activation has previously also been shown to decrease the response of post-synaptic $\mathrm{GABA}_{\mathrm{A}}$ receptors on pyramidal neurons (Seamans et al, 2001), thus working to further diminish the amplitude of eIPSCs. In this study, we also show data that are consistent with this idea as we show that in saline-treated animals not only the frequency, but also the amplitude of mIPSCs was reduced by application of the D2 agonist. In contrast, this effect also did not occur in cocaine-treated animals. Thus, under normal conditions D2R activation seems to reduce both release of GABA by a presynaptic mechanism and may reduce the sensitivity of post-synaptic GABA receptors to decrease the amplitude of the IPSC. On the other hand, direct D1R activation (either through DA in the presence of a D2 antagonist or through a specific D1 agonist) or low extracellular concentrations of DA increased the amplitude of eIPSCs and the frequency of sIPSCs consistent with previous reports in drug-naïve animals (Zhou and Hablitz 1999; Gulledge and Jaffe, 2001; Seamans et al, 2001; Trantham-Davidson et al, 2004; Kroener et al, 2007). As D1R activation also increases the membrane excitability of fast-spiking interneurons, these changes reflect at least in part a presynaptic modulation of excitability and spontaneous action-potential firing (Gorelova et al, 2002; Kroener et al, 2007; Tseng and O'Donnell, 2007).

Repeated cocaine exposure reduced all measures of D2R activity tested here, shifting the time course of DA-induced changes and generally resulting in increases in inhibition. In cells from cocaine-sensitized animals eIPSCs showed an immediate increase in amplitude, which was paralleled by an increase in the frequency of sIPSCs and mIPSCs following application of DA or a D1 agonist. The D2Rspecific reduction in mIPSC frequency was not observed in cocaine-sensitized animals. In acute brain slices action, potential-independent 'miniature' release represents a significant portion of the total number of spontaneous synaptic events (Simkus and Stricker, 2002; Kroener et al, 2007; present data). The lack of D2R modulation of mIPSCs may thus explain the rapid increase in sIPSCs in cocaine animals. This interpretation is further supported by the observation that in cocaine sensitized animals the full agonist DA increased the frequency of mIPSCs, and the fact that during the early-DA effect the amplitude distribution of sIPSCs was shifted to the left, indicating a relative greater contribution of small amplitude mIPSCs to the overall number of synaptic events. DA D1Rs in the terminals of interneurons provide an anatomical substrate for presynaptic modulation of GABA release by DA (Gulledge and Jaffe, 2001; Paspalas and Goldman-Rakic, 2005; Muly et al, 1998). Moreover, the D1R-dependent changes in membrane excitability and action potential-dependent release discussed above likely also contributed to the increase in the frequency of sIPSCs and the increased amplitude of eIPSCs. The reduction in GABA release by D2Rs is functionally similar to stimulation of presynaptic $\mathrm{GABA}_{\mathrm{B}}$ autoreceptors with baclofen, which prevents the initiation of sensitization to cocaine (Steketee and Beyer, 2005). Reductions in the effectiveness of D2R or $\mathrm{GABA}_{B}$ receptor signaling in the PFC of sensitized animals may result from elevated levels of AGS3, and these alterations have been shown to persist though up to 8 weeks of withdrawal (Bowers et al, 2004; Frankowska et al, 2008). AGS3 is a member of a family of G-protein regulators, which sequesters $\mathrm{Gi}-\alpha$ and thereby limits signaling through Gi- $\alpha$-coupled receptors. Finally, D2R activation increased the number of current-evoked spikes in interneurons from saline-treated, but not from cocaine-sensitized animals, providing further evidence for a generalized reduction in Gi-receptor signaling in cocainesensitized animals. However, the results in control animals also indicate an obvious paradox in that it seems that D2R activation can differentially modulate action potentialmediated release of GABA with opposing results (Rétaux et al, 1991). D2R activation decreases the amplitude of eIPSCs (Figure 1; Seamans et al, 2001; Trantham-Davidson et al, 2004), yet it can also increase current-evoked firing in interneurons (Figure 6; Tseng and O'Donnell, 2007; Tseng et al, 2008) and DA release in vivo (Grobin and Deutch, 1998). We replicate two of these findings in adult ( $>72 \mathrm{~d}$ ) saline-treated rats, thus ruling out that these discrepancies solely reflect differences in the developmental state of animals used in previous studies. One potential caveat is that the response to somatic current injection may not adequately reflect the mechanisms that govern spike firing resulting from integration of synaptic inputs. We have recently shown that DA can decrease cortical network activity, even though it consistently increased somatic current-evoked spike firing in individual pyramidal cells (Kroener et al, 2009). Similarly, our results from mIPSC recordings may not fully reflect the effects of DA and D2R activation on synaptic integration, and furthermore, these effects may differ from the post-synaptic effects of DA that regulate spike firing. Thus, clearly more research is needed to unveil the mechanisms, through which D2Rs regulate inhibition in the cortex under normal conditions.

\section{Functional Implications of Altered DA Modulation of Inhibition}

Drug addiction has been conceptualized as a syndrome of impaired response inhibition and salience attribution (Goldstein and Volkow, 2002). Prefrontal control over 
top-down processes is reduced in addiction (Bolla et al, 2004; Briand et al, 2008). Behavioral data indicate that activating the DAergic projection from the VTA to the PFC initiates reinstatement by a glutamatergic projection to the nucleus accumbens core (McFarland et al 2004). On the other hand, blocking all PFC activity through injections of GABA agonists reduces drug seeking (McFarland and Kalivas, 2001; McLaughlin and See, 2003; McFarland et al 2004). Our data using noncontingent delivery of cocaine indicate that changes in the dopaminergic modulation of inhibition contribute to the behavioral sensitization following withdrawal from cocaine. The most parsimonious interpretation of our data is that addiction to cocaine changes the balance between D1 and D2 receptor contributions in DA modulation of inhibition. It has been hypothesized that preferential activation of D1Rs and D2Rs correlates with different PFC activity states that determine the ability of competing motivational representations to drive PFC output to the nucleus accumbens (Seamans et al, 2001; Kalivas et al, 2005; Durstewitz and Seamans, 2008). Interneurons that receive DAergic innervation are well positioned to mediate a switch between different network states (Lapish et al, 2007). At the circuit level, interneurons gate inputs to a network and pattern its outputs (McBain and Fisahn, 2001; Compte et al, 2000; Lapish et al, 2007). DA increases the temporal precision of interneuron firing in the PFC (Tierney et al, 2008), and thus cocaine-induced alterations in DAergic control will disrupt optimal signal processing in the PFC (Kroener et al., 2009). If $\mathrm{D} 2$ regulation of PFC activity is disturbed as a result of repeated cocaine exposure the shift toward D1R signaling may result in attenuated PFC output to subcortical targets (Franklin and Druhan, 2000) and/or a breakdown in optimal processing of salient stimuli that guide behavior (Durstewitz and Seamans, 2008), which can be characterized as hypofrontality and reduced motivation to respond to non-drug-related stimuli. Under these conditions, only very strong motivational stimuli (eg, drug-associated cues) will prevail in activating PFC networks and initiating aimdirected behavior toward this limited set of stimuli (Kalivas et al, 2005). Our data provide physiological evidence for this hypothesized shift in network activation.

\section{ACKNOWLEDGEMENTS}

This research was supported by grants from the National Institutes of Health (DA 014698 to AL; and R21NS056124-02 and P50DA015369-04 subcomponent 84875 to SK). The authors wish to thank Dr Glen Andrews for support during preliminary experiments.

\section{DISCLOSURE}

The authors declare that except for income received from their primary employers, no financial support or compensation was received from any individual or corporate entity over the past 3 years for research or professional service and there are no personal financial holdings that could be perceived as constituting a potential conflict of interest.

\section{REFERENCES}

Abekawa T, Ohmori T, Ito K, Koyama T (2000). D1 dopamine receptor activation reduces extracellular glutamate and GABA concentrations in the medial prefrontal cortex. Brain Res 867: 250-254.

Beyer CE, Steketee JD (2002). Cocaine sensitization: modulation by dopamine D2 receptors. Cereb Cortex 12: 526-535.

Bolla K, Ernst M, Kiehl K, Mouratidis M, Eldreth D, Contoreggi C et al (2004). Prefrontal cortical dysfunction in abstinent cocaine abusers. J Neuropsychiatry Clin Neurosci 16: 456-464.

Bowers MS, McFarland K, Lake RW, Peterson YK, Lapish CC, Gregory ML et al (2004). Activator of G protein signaling 3: a gatekeeper of cocaine sensitization and drug seeking. Neuron 42: 269-281.

Briand LA, Flagel SB, Garcia-Fuster MJ, Watson SJ, Akil H, Sarter $M$ et al (2008). Persistent alterations in cognitive function and prefrontal dopamine D2 receptors following extended, but not limited, access to self-administered cocaine. Neuropsychopharmacology 33: 2969-2980.

Brozoski TJ, Brown RM, Rosvold HE, Goldman PS (1979). Cognitive deficit caused by regional depletion of dopamine in prefrontal cortex of rhesus monkey. Science 205: 929-932.

Carr DB, Sesack SR (2000). GABA-containing neurons in the rat ventral tegmental area project to the prefrontal cortex. Synapse 38: 114-123.

Cauli B, Audinat E, Lambolez B, Angulo MC, Ropert N, Tsuzuki K et al (1997). Molecular and physiological diversity of cortical nonpyramidal cells. J Neurosci 17: 3894-3906.

Compte A, Brunel N, Goldman-Rakic PS, Wang XJ (2000). Synaptic mechanisms and network dynamics underlying spatial working memory in a cortical network model. Cereb Cortex 10: 910-923.

Durstewitz D, Seamans JK (2008). The dual-state theory of prefrontal cortex dopamine function with relevance to catechol-o-methyltransferase genotypes and schizophrenia. Biol Psychiatry 64: 739-749.

Franklin TR, Druhan JP (2000). Involvement of the nucleus accumbens and medial prefrontal cortex in the expression of conditioned hyperactivity to a cocaine-associated environment in rats. Neuropsychopharmacology 23: 633-644.

Frankowska M, Wydra K, Faron-Górecka A, Zaniewska M, oelig;mider M, Dziedzicka-Wasylewska M et al (2008). Alterations in gamma-aminobutyric acid(B) receptor binding in the rat brain after reinstatement of cocaine-seeking behavior. Pharmacol Rep 60: 834-843.

Gao WJ, Wang Y, Goldman-Rakic PS (2003). Dopamine modulation of perisomatic and peridendritic inhibition in prefrontal cortex. J Neurosci 23: 1622-1630.

Goldstein RZ, Volkow ND (2002). Drug addiction and its underlying neurobiological basis: neuroimaging evidence for the involvement of the frontal cortex. Am J Psychiatry 159: 1642-1652.

Gonzalez-Islas C, Hablitz JJ (2001). Dopamine inhibition of evoked IPSCs in rat prefrontal cortex. J Neurophysiol 86: 2911-2918.

Gorelova N, Seamans JK, Yang CR (2002). Mechanisms of dopamine activation of fast-spiking interneurons that exert inhibition in rat prefrontal cortex. J Neurophysiol 88: 3150-3166.

Grobin AC, Deutch AY (1998). Dopaminergic regulation of extracellular gamma-aminobutyric acid levels in the prefrontal cortex of the rat. J Pharmacol Exp Ther 285: 350-357.

Gulledge AT, Jaffe DB (2001). Multiple effects of dopamine on layer $\mathrm{V}$ pyramidal cell excitability in rat prefrontal cortex. J Neurophysiol 86: 586-595.

Jayaram P, Steketee JD (2005). Effects of cocaine-induced behavioural sensitization on GABA transmission within rat medial prefrontal cortex. Eur J Neurosci 21: 2035-2039.

Jayaram P, Steketee JD (2006). Cocaine-induced increases in medial prefrontal cortical GABA transmission involves glutamatergic receptors. Eur J Pharmacol 531: 74-79. 
Kalivas PW, Volkow N, Seamans JK (2005). Unmanageable motivation in addiction: a pathology in prefrontal-accumbens glutamate transmission. Neuron 45: 647-650.

Kroener S, Krimer LS, Lewis DA, Barrionuevo G (2007). Dopamine increases inhibition in the monkey dorsolateral prefrontal cortex through cell type-specific modulation of interneurons. Cereb Cortex 17: 1020-1032.

Kroener S, Phillips PEM, Chandler LJ, Seamans JK (2009). Dopamine modulates recurrent synaptic activity and enhances the signal-to-noise ratio in the prefrontal cortex. PLoS One 4: e6507.

Lapish CC, Kroener S, Durstewitz D, Lavin A, Seamans JK (2007). The ability of the mesocortical dopamine system to operate in distinct temporal modes. Psychopharmacology 191: 609-625.

LeMoine C, Gaspar P (1998). Subpopulations of cortical GABAergic interneurons differ by their expression of D1 and D2 dopamine receptor subtypes. Brain Res Mol Brain Res 58: 231-236.

McBain CJ, Fisahn A (2001). Interneurons unbound. Nat Rev Neurosci 2: 11-23.

McFarland K, Davidge SB, Lapish CC, Kalivas PW (2004). Limbic and motor circuitry underlying footshock-induced reinstatement of cocaine-seeking behavior. J Neurosci 24: 1551-1560.

McFarland K, Kalivas PW (2001). The circuitry mediating cocaineinduced reinstatement of drug-seeking behavior. J Neurosci 21: 8655-8663.

McLaughlin J, See RE (2003). Selective inactivation of the dorsomedial prefrontal cortex and the basolateral amygdala attenuates conditioned-cued reinstatement of extinguished cocaine-seeking behavior in rats. Psychopharmacology 168: 57-65.

Miller CA, Marshall JF (2004). Altered prelimbic cortex output during cue-elicited drug seeking. J Neurosci 24: 6889-6897.

Muly III EC, Szigeti K, Goldman-Rakic PS (1998). D1 receptor in interneurons of macaque prefrontal cortex: distribution and subcellar localization. J Neurosci 18: 10553-10565.

Nogueira L, Kalivas PW, Lavin A (2006). Long-term neuroadaptations produced by withdrawal from repeated cocaine treatment: role of dopaminergic receptors in modulating cortical excitability. J Neurosci 26: 12308-12313.

Paspalas CD, Goldman-Rakic PS (2005). Presynaptic D1 dopamine receptors in primate prefrontal cortex: target-specific expression in the glutamatergic synapse. J Neurosci 25: 1260-1267.

Peters J, LaLumiere RT, Kalivas PW (2008). Infralimbic prefrontal cortex is responsible for inhibiting cocaine seeking in extinguished rats. J Neurosci 28: 6046-6053.

Pierce RC, Bell K, Duffy P, Kalivas PW (1996). Repeated cocaine augments excitatory amino acid transmission in the nucleus accumbens only in rats having developed behavioral sensitization. J Neurosci 16: 1550-1560.

Rétaux S, Besson MJ, Penit-Soria J (1991). Opposing effects of dopamine D2 receptor stimulation on the spontaneous and the electrically evoked release of [3H]GABA on rat prefrontal cortex slices. Neuroscience 42: 61-71.
Santana N, Mengod G, Artigas F (2009). Quantitative analysis of the expression of dopamine D1 and D2 receptors in pyramidal and GABAergic neurons of the rat prefrontal cortex. Cereb Cortex 19: 849-860.

Seamans JK, Gorelova N, Durstewitz D, Yang CR (2001). Bidirectional dopamine modulation of GABAergic inhibition in prefrontal cortical pyramidal neurons. J Neurosci 21: 3628-3638.

Sesack SR, Snyder CL, Lewis DA (1995). Axon terminals immunolabeled for dopamine or tyrosine hydroxylase synapse on GABA-immunoreactive dendrites in rat and monkey cortex. J Comp Neurol 363: 264-280.

Simkus CR, Stricker C (2002). Properties of mEPSCs recorded in layer II neurones of rat barrel cortex. J Physiol 545: 509-520.

Sorg BA, Davidson DL, Kalivas PW, Prasad BM (1997). Repeated daily cocaine alters subsequent cocaine-induced increase of extracellular dopamine in the medial prefrontal cortex. J Pharmacol Exp Ther 281: 54-61.

Steketee JD (2003). Neurotransmitter systems of the medial prefrontal cortex: potential role in sensitization to psychostimulants. Brain Res Brain Res Rev 41: 203-228.

Steketee JD, Beyer CE (2005). Injections of baclofen into the ventral medial prefrontal cortex block the initiation, but not the expression, of cocaine sensitization in rats. Psychopharmacology 180: $352-358$.

Steketee JD, Walsh TJ (2005). Repeated injections of sulpiride into the medial prefrontal cortex induces sensitization to cocaine in rats. Psychopharmacology 179: 753-760.

Sun W, Rebec GV (2005). The role of prefrontal cortex D1-like and D2-like receptors in cocaine-seeking behavior in rats. Psychopharmacology 177: 315-323.

Tierney PL, Thierry AM, Glowinski J, Deniau JM, Gioanni Y (2008). Dopamine modulates temporal dynamics of feedforward inhibition in rat prefrontal cortex in vivo. Cereb Cortex 18: 2251-2262.

Trantham-Davidson H, Neely LC, Lavin A, Seamans JK (2004). Mechanisms underlying differential D1 versus D2 dopamine receptor regulation of inhibition in prefrontal cortex. J Neurosci 24: 10652-10659.

Tseng KY, Lewis BL, Hashimoto T, Sesack SR, Kloc M, Lewis DA et al (2008). A neonatal ventral hippocampal lesion causes functional deficits in adult prefrontal cortical interneurons. J Neurosci 28: 12691-12699.

Tseng KY, O'Donnell P (2007). Dopamine modulation of prefrontal cortical interneurons changes during adolescence. Cereb Cortex 17: $1235-1240$.

Williams JM, Steketee JD (2005). Time-dependent effects of repeated cocaine administration on dopamine transmission in the medial prefrontal cortex. Neuropharmacology 48: 51-61.

Zhou FM, Hablitz JJ (1999). Dopamine modulation of membrane and synaptic properties of interneurons in rat cerebral cortex. J Neurophysiol 81: 967-976.

Supplementary Information accompanies the paper on the Neuropsychopharmacology website (http://www.nature.com/npp) 